I N S T I T U T O

$\mathrm{DE}$

M E D I C I N A

T R O P I C A L

$\mathrm{DE}$

SÃO PAULO

JOURNAL OF THE SÃO PAULO INSTITUTE OF TROPICAL MEDICINE

${ }^{1}$ Fundação Ezequiel Dias, Divisão de Produção Farmacêutica, Belo Horizonte, Minas Gerais, Brazil

${ }^{2}$ Fundação Oswaldo Cruz, Instituto René Rachou, Departamento de Pesquisa Clínica e Políticas Públicas de Doenças InfectoParasitárias, Belo Horizonte, Minas Gerais, Brazil

${ }^{3}$ Fundação Ezequiel Dias, Divisão de Desenvolvimento de Medicamentos, Belo Horizonte, Minas Gerais, Brazil

${ }^{4}$ Fundação Hospitalar do Estado de Minas Gerais, Hospital João XXIII, Centro de Toxicologia, Belo Horizonte, Minas Gerais, Brazil

Correspondence to: Gláucia Cota Fundação Oswaldo Cruz, Instituto René Rachou, Departamento de Pesquisa Clínica e Políticas Públicas de Doenças InfectoParasitárias, Av. Augusto de Lima, 1715, CEP 30.190-009, Belo Horizonte, MG, Brazil

Tel: +553133497700

E-mail: glaucia.cota@ fiocruz.br

Received: 3 June 2021

Accepted: 29 July 2021

\section{A phase IV, prospective, observational study of the clinical safety of snake antivenoms}

\author{
Denise Christie Souto Nogueira ${ }^{(1}$, lara Pinheiro Calil ${ }^{\left({ }^{2}\right.}$, Roberta Márcia \\ Marques dos Santos ${ }^{(13}$, Adebal de Andrade Filho ${ }^{(i)}$, Gláucia Cota ${ }^{\left({ }^{2}\right.}$
}

\section{ABSTRACT}

Snake envenoming is a neglected tropical disease that affects more than 2.7 million people worldwide. The treatment is based on the administration of antivenom composed of heterologous immunoglobulins, species-specific therapy involving the possibility of adverse reactions due to activation of the immune system. Considering the scarcity of prospective studies evaluating the safety of snake antivenoms, this study aimed to describe and characterize adverse events after antivenom infusion in an observational, prospective, single-centre investigation conducted in a referral centre in Brazil. A total of 47 victims of snake envenoming were included in the study, who were mostly men (75\%), with ages ranging from 2 to 83 years. Twenty-two participants (47\%) presented manifestations compatible with infusion-related reactions (IRRs) during or up to two hours after $F\left(a^{\prime}\right)_{2}$ heterologous immunoglobulin infusion. The most common clinical manifestation related to the infusion was a diffuse cutaneous rash (82\%), followed by respiratory manifestations $(46 \%)$ and facial swelling (23\%). In four cases (9\%), IRR were considered serious adverse events (SAE), characterized by haemodynamic instability, airway obstruction or hypoxia. Only one patient developed symptoms compatible with serum sickness. Although almost half of the patients treated with antivenom sera experienced IRRs, the SAE rate was 9\%; in all cases, the adverse reaction was reversible by using supportive treatment, and there were no deaths. The results have shown that there is much to improve in the antivenom production process to obtain a more purified and specific product. Even so, a timely antivenom serum administration managed by well-trained health teams is safe and prevents complications after snake-related accidents.

KEYWORDS: Antivenoms. Snakebites. Snake envenoming. Safety.

\section{INTRODUCTION}

The World Health Organization (WHO) recognizes snake envenoming as one of the 20 neglected tropical diseases and, despite the inaccuracy of the available data, estimates that approximately 5.4 million people are bitten annually. According to the WHO, 1.8-2.7 million people develop clinical illness, and 81,000 to 138,000 die from snakebite complications $^{1,2}$. Low-income populations living in rural areas of tropical countries and with little access to health care, including agricultural workers, working children and people living in poorly constructed houses, are high-risk groups for snakebites $^{3,4}$. In Brazil, accidents involving venomous animals have been considered a a notifiable event since 2010. Between 2007 and 2019, 367,128 snake envenoming cases and 1,481 deaths were reported to the Brazilian Ministry of Health through the National Reportable Disease Information System (SINAN) ${ }^{5}$. Snake envenoming 
morbidity is mainly related to local reactions, ranging from skin and soft tissue injuries and scarring to deeper muscle, connective tissue and vascular necrosis leading to substantial loss of limb function or even amputation ${ }^{6}$. Some of these complications require prolonged hospitalization and extensive rehabilitation, which implies the loss of working days and compromises the family income of self-employed and socially vulnerable workers ${ }^{7}$. Less frequent but more worrying, systemic complications have also been reported, such as kidney damage and cardiocirculatory collapse ${ }^{6}$. Antivenom sera are clearly effective to reduce the case fatality and morbidity of snakebites ${ }^{8,9}$. Thus, a core component of any strategy to address this neglected condition is to improve the access to high-quality antivenoms ${ }^{10}$. In this context, the complete recognition of the antivenom safety profile is essential to guarantee confidence and adherence of health professionals to the recommendation of immediate application of the antisera. Prospective studies designed to assess the rate of adverse events (AEs) associated with antivenom are scarce ${ }^{11-14}$. Most of the available data come from retrospective descriptive studies that report a wide range of variation in the antivenom reaction rate, between $3 \%$ and $88 \%{ }^{15,16}$. Other AEs, including serum sickness, are even less well evaluated. Methodological heterogeneity, different monitoring approaches and adverse event classification systems, in addition to differences among studied populations, genera of snakes and serum production specificities, account for the discrepancies and contribute to the lack of strong management recommendations. In turn, epidemiological surveillance systems and health regulatory agencies have not been successful in compiling the rate of reactions related to antivenom sera, even in countries where this monitoring is mandatory, as in Brazil ${ }^{10,15}$. This study aims to report the incidence and to characterize the pattern of AEs related to snake antivenom in a Brazilian referral centre by means of a prospective and standardized methodology.

\section{MATERIALS AND METHODS}

\section{Study design, setting and eligibility criteria}

An observational, prospective, single-centre study was conducted at the toxicology referral centre of Hospital Joao XXIII (CT-HJXXIII), Fundacao Hospitalar do Estado de Minas Gerais (FHEMIG), in Belo Horizonte, Minas Gerais State, Brazil. Between January and December 2019, victims of envenoming involving all genera of venomous snakes were consecutively recruited and followed-up for approximately three weeks after the antivenom administration. Patients who did not receive antivenom sera at the referral centre and those who did not agree or who did not have the cognitive conditions to decide regarding their participation in the study were excluded. There was no sample size calculation. The study was designed to describe the adverse events recorded in a typical year following the Strengthening the Reporting of Observational studies in Epidemiology (STROBE) Statement, and the international guideline for reporting observational studies (STROBE Statement. The checklist is available in the Supplementary Material Table S1) ${ }^{17}$.

\section{Ethics Statement}

This study was approved by the Ethics Committee of the Instituto Rene Rachou, Fundacao Oswaldo Cruz, CAAE $\mathrm{N}^{\circ}$ 91236318.0.0000.5091 and by the Research Ethics Committee of the Fundacao Hospitalar de Minas Gerais, CAAE $\mathrm{N}^{\circ}$ 91236318.0.3001.5119, approval numbers 2.833 .643 and 3.007.478, respectively. Informed consent was obtained from all human adult participants and from parents or legal guardians of minors together with the approved consent of the Ethical Commission. A consent term was applied to study participants of legal age. To children over the age of seven and adolescents an assent term was applied in addition to the consent obtained from their parents or legal guardians.

\section{Antivenom therapy}

The participants received snake antivenoms based on the type $\mathrm{F}\left(\mathrm{ab}\right.$ ') ${ }_{2}$ fraction of specific and purified heterologous immunoglobulins distributed by the National Program of Immunization (PNI), a national coordinated action of the Brazilian Government. Four public laboratories are responsible for the national serum production: Instituto Vital Brazil, Instituto Butantan, Centro de Producao e Pesquisa de Imunobiologicos (CCPI) and Fundacao Ezequiel Dias (FUNED). They use basically the same production protocol. These laboratories independently produce the three types of serum for the most prevalent venomous species in Brazil: Crotalic, Bothropic, Elapid, Lachesis (anti-Bothropic Lachesis) and a mixed antiBothropic and Crotalic antivenom for accidents involving unidentified species. The antivenom serum is based on plasma of horses hyperimmunized with venom from known snake species as immunogens. The number of ampoules used for treatment was determined based on the clinical severity of the patient, according to recommendations of the Ministry of Health of Brazil ${ }^{18}$. In general, the snake genus involved in the envenoming is recognized based on the patients' clinical and laboratory patterns. The main clinical abnormalities of Bothropic accidents are exuberant 
bite site signs, including edema, pain, blisters, necrosis and bleeding, and no neurotoxic manifestations. Laboratory tests in general revealed a prolongation of the prothrombin time, fibrinogen consumption and thrombocytopenia. On the other hand, in Crotalic accidents, local alterations are mild, and manifestations resulting from neuromuscular blockage predominate, such as eyelid ptosis, dysphagia and respiratory failure. In approximately $30 \%$ of the cases, the victims took the snake to the healthcare unit for identification.

\section{Data sources and outcomes}

Baseline clinical and demographic data, medical history, snake accident characteristics and information about the treatment administered to the patients were collected. All participants had their clinical and laboratory parameters actively monitored using a specific datasheet at five predefined intervals during hospitalization (on admission and 2, 12, 24, and $48 \mathrm{~h}$ after the end of the antivenom infusion and during the last day of hospitalization). In each assessment, all clinical and laboratory information from the immediately preceding interval was gathered through interviews and physical examinations of the patients, reviews of medical records and laboratory tests to help us assessing the time of onset of the adverse events in relation to the infusions. After the hospital discharge, a telephone contact was made around the $24^{\text {th }}$ day ( \pm 3 days) from the date of the snakebite accident using a standardized form to collect AEs. The outcomes of interest were adverse events, according to the organ system, intensity, seriousness and causal relationship with the antivenom serum therapy.

\section{AEs definition and classifications}

Any new or worsened sign/symptom and laboratory abnormality that arose after the beginning of the antivenom infusion were considered as AEs and registered using the terminology established in the Common Terminology Criteria for Adverse Events (CTCAE) classification, Version $5.0^{19}$. These events were classified in five categories characterized in relation to the affected organ and system and the intensity of symptoms based on the same classification system (mild, moderate, severe, lifethreatening, death related to the AE). On the other hand, seriousness refers to the presence of a life-threatening condition, and in this study, it was defined according to the National Health Surveillance Agency of Brazil (ANVISA) criteria $^{20}$. Based on the current Brazilian definition, a serious adverse event (SAE) is an event that meets one of the following criteria: results in death, is life-threatening, requires inpatient hospitalization or prolongation of existing hospitalization, results in persistent or significant disability/incapacity, is a congenital anomaly/birth defect or involves the transmission of a microorganism. The causal relationship between AEs and antivenom was assessed according to the Uppsala Monitoring Center (UMC) criteria proposed by the World Health Organization (WHO-UMC) ${ }^{21}$. This system has been developed in consultation with the National Centres participating in the Program for International Drug Monitoring, taking into account the clinical-pharmacological aspect, temporality, response to withdrawal, rechallenge and the existence of another recognized cause of the AE. Based on these aspects, the following causality categories are defined: certain, probably, possible, unlikely or unclassified. According to CTCAE, any adverse reaction during an infusion of a pharmacological or biological substance should be designated as an infusion-related reaction (IRR). Thus, in this study, for standardization purposes, we determined that all worsening clinical signs and symptoms manifested from the beginning of antivenom administration until two hours after the end of the infusion, excluding those unequivocally recognized as caused by the venom toxin, such as bite site edema, blisters, paresthesia and skin necrosis, would be considered as IRR. All the manifestations gathered in the unique term IRR were also recorded separately for a complete description of the spectrum of signs and symptoms observed.

\section{Statistical methods}

The descriptive analysis included the absolute and relative frequencies for categorical variables and the median and $25-75 \%$ interquartile range (IQR) for continuous variables. Comparisons between categorical variables were performed using the Fisher's exact test. For the comparison of continuous variables, ANOVA or nonparametric tests were used, depending on the data distribution pattern. Two outcomes were defined as of interest for the univariate and the multiple analyses: the occurrence of SAE and IRR. Variables associated with the outcome of interest at a significance level of 0.25 were included in a multiple model, respecting the premise of independence between the variables. The significance was set at $5 \%$ in all tests. The analyses were carried out using the software Statistical Package for the Social Sciences - SPSS, version 23.0 (SPSS Inc., Chicago, IL, USA).

\section{RESULTS}

Between January 2 and December 31, 2019, 84 snakebite accident victims were admitted to CT-HJXXII. Of 
this total, 47 met the eligibility criteria and were included in the study (Figure 1). The demographic characteristics of the patients are described in Table 1. The age of the patients ranged from 2 to 83 years, and most of them were men $(35 / 47 ; 75 \%)$. Agricultural activities represented the occupation of 15/34 (44\%) victims of working age. The education level was generally low: $64 \%$ of patients reported the elementary school level, and four patients were illiterate. Thirty-one patients (66\%) had comorbidities, among whom $13(8 \%)$ were taking medications chronically. Eighteen participants (38\%) reported regular alcohol consumption, arbitrarily defined here as more than twice a week.

In this series, the Crotalus genus predominated and was responsible for $53 \%$ of thecases, followed by Bothrops, with $45 \%$ of cases. In one snakebite accident the snake genus was not identified, and the victim was treated with antiBothropic-Crotalic sera. Almost half of the accidents were classified as severe (49\%), 25\% as moderate and $25 \%$ as mild in terms of clinical severity. Most envenomings occurred in rural areas $(83.0 \%)$. The median interval between the occurrence of the bites and the hospital admission was 4:09 (IQR 2:30-9:53) hours, while the median time between the bites and the beginning of the antivenom sera administration was 6:47 (IQR 4:45-20:15) hours. Eight participants received sera produced by the Instituto Vital Brazil, and
Table 1 - Demographic and clinical characteristics of the participants.

\begin{tabular}{lc}
\hline Feature & Distribution (\%) \\
\hline Male gender & $35(74.5)$ \\
Median age (IQR) & $45(24.5-55)$ \\
\hline Education level $^{*}$ & \\
Elementary school $^{*}$ & $27(64.3)$ \\
High school education & $11(26.2)$ \\
Higher education & 0 \\
Illiterate & $4(9.5)$
\end{tabular}

\section{Associated conditions}

Hypertensive disease

$10(21.3)$

Smoking

$6(12.8)$

Chronic use of medication

$13(27.7)$

Chronic pulmonary disease

$2(4.3)$

Chronic kidney disease

$3(6.4)$

Regular alcohol consumption \#

18 (38.3)

Allergy

$1(2.1)$

Diabetes mellitus

$3(6.4)$

Some other associated conditions

Occupation**

Agricultural activity

$13(27.7)$

Services and industry

$15(44.0)$

IQR $=$ interquartile range; ${ }^{*} 5$ children under 7 years of age were not included; ${ }^{* *}$ only adults included; \# average alcohol consumption greater than twice a week.

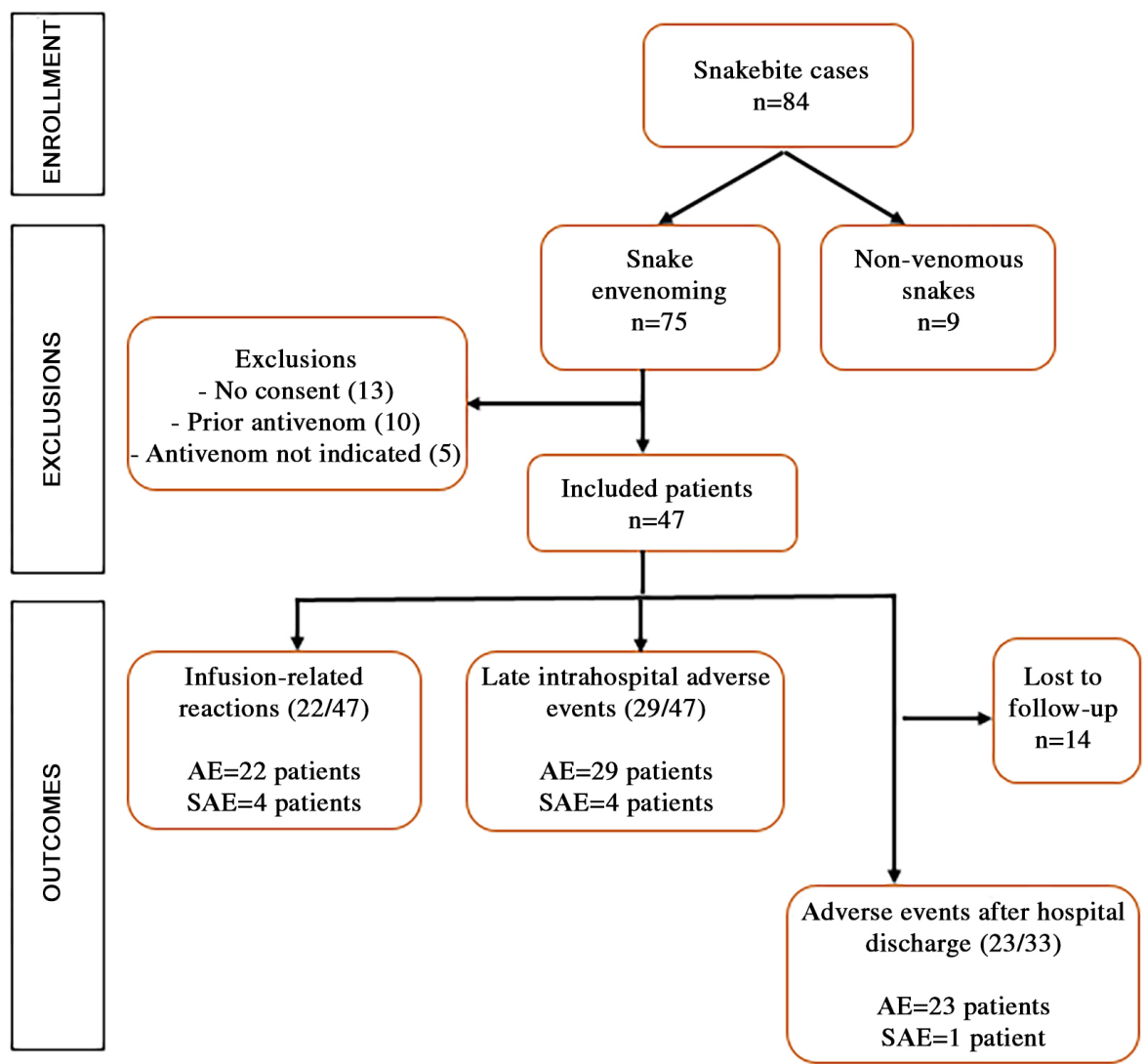

Figure 1 - Patient's enrollment, exclusions, and outcomes; $A E$ = adverse event; $S A E$ = serious adverse event. 
38 received sera produced by the Instituto Butantan. One participant, who required a complementation of the antivenom sera due to the worsening of his clinical condition during hospitalization (clinical seriousness reclassification), received sera produced by both laboratories. The median duration of serum infusion was 30 (IQR 20-33) minutes. Four patients had received part of the sera in healthcare units near the accident site before their admission to the reference service CT-HJXXIII. Although the prescription of premedication had not been routinely established at the referral centre, one patient received corticosteroid (hydrocortisone) and antihistamine (promethazine) drugs, and two others received dipyrone and lidocaine (2\%) before the antivenom serum infusion at the discretion of the medical staff. The AEs observed were organized in three groups: 1. Infusion-related reaction; 2. Late in-hospital events and 3. After hospital discharge events.

\section{Infusion-related reactions}

Twenty-two participants (47\%) had some manifestations compatible with IRRs during or up to two hours after the antivenom infusion. Two other participants had clinical abnormalities that are classic signs of the activity of the venom toxin (eyelid ptosis with visual blur and worsening of edema and paresthesia at the bite site), which were not considered IRRs. A complete description of the manifestations registered as IRR is shown in Table 2. The most frequent clinical manifestation, present in $82 \%$ of the 22 patients, was a diffuse cutaneous rash, either

Table 2 - Main characteristics of the infusion-related reactions.

\begin{tabular}{|c|c|c|c|c|c|}
\hline PID & Clinical manifestations & Seriousness of EA & Type of antivenom & $\begin{array}{l}\text { Intensity } \\
\text { of EA }\end{array}$ & $\begin{array}{l}\text { Causal association } \\
\text { with antivenom }\end{array}$ \\
\hline$\# 1$ & diffuse cutaneous rash & Non-serious & Anti-Bothrops & 1 & Probable \\
\hline$\# 4$ & diffuse cutaneous rash & Non-serious & Anti-Crotalus & 2 & Probable \\
\hline$\# 6$ & $\begin{array}{l}\text { diffuse cutaneous rash, cough, facial } \\
\text { swelling }\end{array}$ & Non-serious & Anti-Crotalus & 2 & Probable \\
\hline$\# 8$ & diffuse cutaneous rash, cough & Non-serious & Anti-Crotalus & 2 & Probable \\
\hline$\# 9$ & dizziness & Non-serious & Anti-Crotalus & 1 & Possible \\
\hline$\# 11$ & dizziness & Non-serious & Anti-Bothrops & 1 & Possible \\
\hline$\# 12$ & diffuse cutaneous rash, throat tightness & Non-serious & Anti-Crotalus & 2 & Probable \\
\hline$\# 13$ & diffuse cutaneous rash & Non-serious & Anti-Bothrops & 1 & Probable \\
\hline$\# 19$ & diffuse cutaneous rash & Non-serious & Anti-Crotalus & 2 & Probable \\
\hline$\# 20$ & diffuse cutaneous rash, cough & Non-serious & Anti-Bothrops & 2 & Probable \\
\hline$\# 22$ & diffuse cutaneous rash, facial swelling & Non-serious & Anti-Crotalus & 2 & Probable \\
\hline$\# 23$ & diffuse cutaneous rash & Non-serious & Anti-Bothrops & 2 & Probable \\
\hline \#32 & $\begin{array}{l}\text { diffuse cutaneous rash, tachycardia, } \\
\text { hypothermia, thigh pain, sweating, } \\
\text { tachypnea, breathing effort, hypoxia, } \\
\text { facial swelling, hypotension }\end{array}$ & Serious & AntiCrotalus & 4 & Certain \\
\hline \#34 & $\begin{array}{l}\text { diffuse cutaneous rash, tachypnea, } \\
\text { respiratory effort, hypoxia, cough }\end{array}$ & Serious & Anti-Crotalus & 4 & Certain \\
\hline \#35 & $\begin{array}{l}\text { diffuse cutaneous rash, facial swelling, } \\
\text { throatightness }\end{array}$ & Non-serious & Anti-Crotalus & 2 & Probable \\
\hline \#37 & $\begin{array}{l}\text { diffuse cutaneous rash, hoarseness, } \\
\text { cough, tachycardia, bronchospasm }\end{array}$ & Serious & Anti-Bothrops & 4 & Probable \\
\hline \#39 & tremor, chills, vomiting & Non-serious & $\begin{array}{l}\text { Anti-Bothrops-anti- } \\
\text { Crotalus }\end{array}$ & 1 & Probable \\
\hline$\# 41$ & loin pain & Non-serious & Anti-Crotalus & 1 & Possible \\
\hline$\# 43$ & diffuse cutaneous rash, vomiting & Non-serious & Anti-Bothrops & 1 & Probable \\
\hline$\# 44$ & diffuse cutaneous rash & Non-serious & Anti-Bothrops & 2 & Probable \\
\hline \#46 & $\begin{array}{l}\text { diffuse cutaneous rash, hypoxia, } \\
\text { hypotension, chest pain, urinary } \\
\text { retention }\end{array}$ & Serious & Anti-Crotalus & 4 & Probable \\
\hline \#48 & $\begin{array}{c}\text { diffuse cutaneous rash, facial swelling, } \\
\text { throat tightness }\end{array}$ & Non-serious & Anti-Crotalus & 2 & Probable \\
\hline
\end{tabular}

$\mathrm{PID}=$ participant identification. 
pruritic or not, followed by some respiratory manifestations (46\%), such as cough, tachypnea, breathing effort (use of accessory muscles of respiration, stridor, grunting, or nasal flaring), hypoxia (oxygen saturation $<90 \%$ ), throat tightness, wheezing and facial swelling (23\%). Less frequent manifestations were vomiting, dizziness, tremor, localized muscle pain, hypotension ( 2 cases each), and urinary retention (1 case). Regarding the seriousness, four of the 22 infusion reactions were classified as clinically significant or serious, representing $18 \%$ of the cases with IRRs and $9 \%$ of the total snake victims. The serious adverse events (SAE) consisted of vital parameter abnormalities, namely, hypoxia or hypotension. For the treatment of IRRs, fifteen patients $(68 \%, 15 / 22)$ received corticosteroids and antihistamines, and six patients $(27 \%$, $6 / 22$ ) required intravenous administration of adrenaline. In seven cases (32\%), the antivenom infusion was temporarily interrupted and resumed after the symptoms resolution. In two cases, the adverse events worsened or resumed with the reintroduction of the antivenom. All patients evolved with complete regression of the signs and symptoms of the infusion reaction, and no deaths were recorded. A causal relationship with the antivenom sera was considered possible in three patients, probable in 17 patients and certain in two patients.

\section{Late in-hospital adverse events}

The median hospital stay was 3 days, ranging from 2 to 21 days. During the interval between two hours after the end of the antivenom infusion and the hospital discharge, 29 patients presented with new or worsening of bite site inflammatory signs, in all cases assumed to be secondary to the damage caused by the snake venom or by a secondary bacterial infection. In addition, 16 patients presented 24 new clinical abnormalities that were not related to the bite. Sixteen of these occurrences were considered as a consequence of the venom damage and not as true adverse events, as they were compatible with the progression of the clinical syndrome (envenomation) that was already present before the antivenom infusion. These abnormalities were typical manifestations of venom neurotoxicity, such as cranial nerve palsies (causing eyelid ptosis, photophobia, facial paralysis and dysarthria), muscle injury and rhabdomyolysis, clinically manifested as myalgia, elevation of serum creatine phosphokinase level, acute renal failure or edema in two or more sites. Excluding these abnormalities due to venom, eight adverse events were observed in this post-serum infusion period; in three cases, the event was fever, attributed to secondary bacterial infections at the bite site. The other five adverse events were acute disorientation
( 1 case), vertigo ( 1 case), cough ( 2 cases) and isolated fever ( 1 case). All the events were mild to moderate in intensity, none met the seriousness criterion, and the association with the antivenom therapy was considered possible according to the WHO-UMC classification ${ }^{21}$.

\section{Post-hospital discharge adverse events}

After hospital discharge, 33 of the 47 participants could be contacted by telephone, representing a follow-up loss of 30\%. Twenty-three (70\%) patients reported at least one new clinical abnormality since the hospital discharge. Twenty-one patients reported complications at the bite site, 12 patients reported a complaint that was not related to the bite site, and 10 patients had both, new local and systemic clinical manifestations. Five patients reported fever, four of whom were treated with antibiotics for secondary bacterial infections at the bite site. There was one victim of Crotalus envenoming who presented with extensive soft tissue necrosis at the bite site (foot), requiring rehospitalization and surgical debridement, an occurrence that met the SAE criteria. Another patient presented with fever, arthralgia and generalized adenomegaly, a set of manifestations compatible with serum sickness. He was treated with oral corticosteroids on an outpatient basis, with complete regression of symptoms.

\section{Serious adverse events}

In total, 10 of the 47 patients (21\%) had AEs classified as serious. In five patients, the seriousness criterion was the prolonged hospitalization due to severe limb edema at risk of the compartment syndrome. Three of these patients were diagnosed with overlapping bacterial infections at the bite site and required intravenous antibiotic therapy, all of whom were victims of Bothrops envenoming. In addition, there was one SAE after hospital discharge, a victim of a Crotalus envenom who presented with infection and necrosis at the bite site requiring rehospitalization and surgical treatment. For all six cases requiring prolongation or a new hospitalization (severe edema and soft tissue necrosis), a causal relationship with the antivenom was considered unlikely, and the complications were attributed to the destructive action of the snake's venom. Thus, among 10 patients presenting with SAEs, six had complications clearly resulting from the envenomation. In turn, events that were not related to the snake venom occurred in four patients and consisted of a life-threatening hemodynamic or respiratory manifestation (hypotension, hypoxia or airway obstruction) during the antivenom infusion, which corresponded to $9 \%$ of the patients evaluated in this study. 
Three of these patients were victims of Crotalus snakes, and the other patient had a Bothrops envenomation. Based on the WHO criteria ${ }^{21}$, the causal link between the antivenom and the SAE presented by these four participants was considered "probable" in two cases and "certain" in the other two. All 10 SAEs observed are described in detail in Table 3.

In the univariate and multivariate analyses, no factors associated with the occurrence of IRRs were identified. In turn, two conditions were shown to be associated with the occurrence of SAEs: "snakebite occurring in a rura area" and "incomplete antivenom administration prior to the hospital admission" (Tables 4 and 5). No factor was identified as related to the occurrence of a serious IRR.

\section{DISCUSSION}

The main contribution of this study is the presentation of the safety profiles of the snake antivenoms used in Brazil through a prospective, active and standardized methodology to report adverse events. Different from other snakebite hotspots in the world, such as Southeast Asia, where, in addition to insufficient antivenom production, populations still deal with low effectiveness of antivenoms due to the lack of specific antiserum for all the numerous local snake species ${ }^{22}$, in Brazil, the challenge is to promote decentralized healthcare and access to antivenoms, which requires trained health teams and complete data on the antivenoms safety pattern. Our most important observation was the confirmation of a high rate of AEs related to antivenoms: almost half of the patients $(22 / 47,47 \%)$ presented with IRRs, a manifestation compatible with the type I hypersensitivity reaction. This early reaction is possibly mediated by previously formed IgE antibodies, whose binding with heterologous serum proteins promote the release of vasoactive mediators and the typical clinical manifestations of an allergic reaction (nasal and ocular congestion, nasal obstruction, wheezing, urticaria, angiedema, anaphylaxis or anaphylactic shock) ${ }^{12,15,23,24}$. A postulated alternative mechanism is also a variant form of the type I hypersensitivity reaction, the anaphylactoid reaction. In this case, mediators other than IgE, such as the complement system factors are involved in the stimulation of mast cells, also resulting in their degranulation and histamine release. Despite presenting different mechanisms, from a clinical point of view, the two conditions are undistinguishable ${ }^{15,16,23,25,26}$. For reactions mediated by IgE, however, it is assumed that the individual has been previously sensitized ${ }^{15,16}$, which makes this complication theoretically preventable by optimizing the purity of the antivenom sera if we consider cross-reactions with other proteins to be the triggering mechanism of the cascade of events. For this reason, the recognition of the products prone to infusion reactions can guide changes and improvement in different stages during the production of this immunobiological agent.

Early reactions associated with the antivenom infusion are expected events, considering the protein composition and the heterologous nature of the snake antisera. In our observations, the most common clinical manifestation of IRR was a diffuse cutaneous rash, present in $82 \%$ of cases, followed by respiratory manifestation in $46 \%$ and facial swelling in $23 \%$. The predominance of allergic

Table 3 - Main characteristics of the serious adverse events.

\begin{tabular}{|c|c|c|c|c|}
\hline PID & Adverse event description & Intensity & Seriousness criterium & $\begin{array}{l}\text { Causal nexus with } \\
\text { antivenom }\end{array}$ \\
\hline \multirow{2}{*}{$\# 1$} & Bite site edema & 3 & Prolonged hospitalization & unlikely \\
\hline & Bacterial infection at the bite site & 3 & Prolonged hospitalization & unlikely \\
\hline \multirow{2}{*}{$\# 10$} & Bite site edema & 3 & Prolonged hospitalization & unlikely \\
\hline & Bacterial infection at the bite site & 3 & Prolonged hospitalization & unlikely \\
\hline \multirow[t]{2}{*}{$\# 11$} & Bite site edema & 3 & Prolonged hospitalization & unlikely \\
\hline & Bacterial infection at the bite site & 3 & Prolonged hospitalization & unlikely \\
\hline$\# 12$ & Bacterial infection and necrosis at the bite site & 3 & Re-hospitalization & unlikely \\
\hline$\# 16$ & Bite site edema & 3 & Prolonged hospitalization & unlikely \\
\hline$\# 20$ & Bite site edema & 3 & Prolonged hospitalization & unlikely \\
\hline$\# 32$ & IRR (hypoxia and hypotension) & 4 & Life threatening event & Certain \\
\hline$\# 34$ & IRR (hypoxia) & 4 & Life threatening event & Certain \\
\hline$\# 37$ & IRR (bronchospasm) & 4 & Life threatening event & Probable \\
\hline$\# 46$ & IRR (hypoxia and hypotension) & 4 & Life threatening event & Probable \\
\hline
\end{tabular}

PID = participant identification . 
Table 4 - Univariate analysis for the factors associated with the occurrence of serious adverse events.

\begin{tabular}{|c|c|c|c|}
\hline & $\begin{array}{l}\text { Patients who did } \\
\text { not present SAE } \\
(\%) n=37\end{array}$ & $\begin{array}{l}\text { Patients who } \\
\text { presented SAE } \\
(\%) n=10\end{array}$ & $p$-value $* *$ \\
\hline Median age (IQR & $45(24-56)$ & $40(24-55)$ & 0.779 \\
\hline \multirow{2}{*}{ Gender } & $27(73.0)$ & $8(80.0)$ & 1.0 \\
\hline & $10(27.0)$ & $2(20.0)$ & \\
\hline \multirow{3}{*}{ Education level } & $6(16.2)$ & $3(30.0)$ & 1.0 \\
\hline & $22(59.5)$ & $5(50.0)$ & \\
\hline & $9(24.3)$ & $2(20.0)$ & \\
\hline \multirow{3}{*}{ Envenoming occurrence zone } & $33(89.2)$ & $6(60.0)$ & 0.080 \\
\hline & $3(8.1)$ & $3(30.0)$ & \\
\hline & $1(2.7)$ & $1(10.0)$ & \\
\hline \multirow{2}{*}{ Professional activity } & $10(27.0)$ & $5(50.0)$ & 0.25 \\
\hline & $27(73.0)$ & $5(50.0)$ & \\
\hline \multirow{2}{*}{ Bite site } & $28(75.7)$ & $9(90.0)$ & 0.263 \\
\hline & $9(24.3)$ & $1(10.0)$ & \\
\hline Hypertension & $9(24.3)$ & $1(10.0)$ & 0.664 \\
\hline Smoking & $4(10.8)$ & $2(20.0)$ & 0.613 \\
\hline Chronic use of medication & $11(29.7)$ & $2(20.0)$ & 0.703 \\
\hline Chronic lung disease & $2(5.4)$ & 0 & 1.0 \\
\hline Chronic kidney disease & $3(8.1)$ & 0 & 1.0 \\
\hline Self-reported regular consumption of alcohol & $15(40.5)$ & $3(30.0)$ & 0.800 \\
\hline Report of any previous allergy & $1(2.7)$ & 0 & 1.0 \\
\hline Diabetes mellitus & $2(5.4)$ & $1(10.0)$ & 0.521 \\
\hline Chronic liver disease & $1(2.7)$ & 0 & 1.0 \\
\hline Chronic heart disease & 0 & $2(20.0)$ & 0.042 \\
\hline Any associated chronic condition & $27(73.0)$ & $4(40.0)$ & 0.068 \\
\hline \multirow{3}{*}{ Snake genus } & $15(40.5)$ & $6(60.0)$ & 0.587 \\
\hline & $21(56.8)$ & $4(40.0)$ & \\
\hline & $1(2.7)$ & 0 & \\
\hline Antivenom infusion prior to the hospital admission & $1(2.7)$ & $3(30.0)$ & 0.026 \\
\hline Median length of hospital stay (IQR), days & $3(2-4)$ & $4(3-6)$ & 0.089 \\
\hline Progression in the envenoming clinical classification after hospital admission & $5(13.5)$ & $1(10.0)$ & 1.0 \\
\hline $\begin{array}{l}\text { Complementation of antivenom sera due to change of the envenoming } \\
\text { clinical classification (\%) }\end{array}$ & $5(13.5)$ & 0 & 0.569 \\
\hline \multirow[b]{4}{*}{ Median duration of antivenom sera infusion (IQR) minutes } & $11(29.7)$ & $1(10.0)$ & 0.134 \\
\hline & $11(29.7)$ & $1(10.0)$ & \\
\hline & $15(40.5)$ & $8(80.0)$ & \\
\hline & $30(20-31)$ & $20(18-80)$ & 0.965 \\
\hline $\begin{array}{l}\text { Median time elapsed between the snakebite and hospital admission (IQR) } \\
\text { in hours: minutes }\end{array}$ & $\begin{array}{l}04: 09(02: 34- \\
08: 38)\end{array}$ & $\begin{array}{l}05: 33(02: 04- \\
25: 15)\end{array}$ & 0.779 \\
\hline $\begin{array}{l}\text { Median time elapsed between the snakebite and the administration of } \\
\text { antivenom sera (IQR) in hours: minutes }\end{array}$ & $\begin{array}{l}06: 40(04: 35- \\
18: 46)\end{array}$ & $\begin{array}{l}09: 35(04: 39-25: \\
43)\end{array}$ & 0.252 \\
\hline
\end{tabular}

${ }^{*}$ children under 7 years of age were not included; ${ }^{\star \star}$ Fisher Exact test

Table 5 - Multiple model of the factors associated with the occurrence of serious adverse events.

\begin{tabular}{lcccc}
\hline \multirow{2}{*}{ Variables in the model } & \multirow{2}{*}{ p value } & \multirow{2}{*}{ Odds Ratio } & \multicolumn{2}{c}{$95 \% \mathrm{Cl}$} \\
\cline { 3 - 5 } & & & Lower limit & Upper limit \\
\hline Incomplete antivenom administration prior to the hospital admission & 0.008 & 32.00 & 2.49 & 411.43 \\
Snakebite accident occurring in a rural area & 0.011 & 10.67 & 1.72 & 65.99 \\
\hline
\end{tabular}

$\mathrm{Cl}=$ confidence interval. 
skin manifestations was similar to that reported in two prospective studies conducted in Bangladesh and Sri Lanka $^{27,28}$. Thus, the estimated rates of total AEs and SAEs vary enormously, and are clearly related to the lack of uniformity of the event definitions. The terms anaphylaxis, hypersensitivity reaction, infusional reaction and allergic reaction are common designations for adverse reactions due to antivenoms. According to a review performed by Leon et al. ${ }^{15}$, who collected 25 studies addressing the safety profile of antivenoms produced in Brazil, Colombia, Nigeria, Africa, the United States, France, Sri Lanka and Thailand, the average rate of early "allergic reactions" is approximately $20 \%$, ranging from $3 \%$ to $88 \%{ }^{15}$. In turn, a review focusing on Crotalus antivenoms used in North America that included 11 studies carried out between 1997 and 2010 estimated the incidence of immediate hypersensitivity reactions to be $8 \%{ }^{29}$. In Brazil, the rate of IRRs related to snake antivenom has been estimated at $14 \%^{30}$ to $45.9 \%^{31}$ in studies performed in Minas Gerais, and at $24 \%^{26}$ to $87 \%^{32}$ in studies carried out in Sao Paulo State. In Northern Brazil, the region with the highest snake envenoming incidence in the country ${ }^{5}$, IRR rates were estimated between $15.6 \%{ }^{33}$ and $53 \%{ }^{34}$. In addition to the terminology, there are many other reasons that explain the great variation in the IRR rates among studies, including those intrinsically related to the antivenom specificities (snake genus, production protocol) and to the antiserum administration procedures, which can differ regarding the use of premedication, the antivenom dilution and the infusion rate. In addition, the strategy adopted for recording and classifying complications may also justify part of this wide variation in the AE rate. In this sense, one factor possibly related to the high rate of IRRs observed here was the prospective study design and the active $\mathrm{AE}$ surveillance performed.

Despite the high frequency of AEs, the rate of SAEs effectively associated with antivenom sera was significantly lower, estimated at $9 \%$. This finding diverges significantly from the severe systemic hypersensitivity reaction rates of over 30\% reported in other studies involving different snake genera. Despite different SAE rates among studies, the reactions related to antivenoms are universally described as reversible and showing a favorable prognosis if properly handled ${ }^{35}$. In this series, all SAEs evolved with complete resolution, and no permanent disabilities or deaths were recorded. The risk of SAE was confirmed to be higher among victims of snakebites in rural areas, and among those who reported incomplete antivenom therapy prior to the hospital admission, two circumstances that could be understood as a proxy for snakebite occurrence in remote areas, which implies a delay in the application of a timely therapy, leading to extensive tissue damage ${ }^{16}$. In this context, a longer interval between a snakebite and the hospital admission would be expected for patients presenting with SAEs, but this was not confirmed, possibly due to the small sample size.

Regarding late antivenom reactions, only one case presenting with symptoms compatible with serum sickness was identified in this study, corresponding to an estimated incidence of $2 \%$, which is apparently lower than the 5 to $10 \%$ described by other authors ${ }^{16,29,36}$. This is an important complication related to the administration of immunobiological products attributed to a type III hypersensitivity reaction ${ }^{16,37}$. This finding requires cautious interpretation, considering that the search for serum sickness occurrence, in contrast to what was performed in the hospital phase of follow-up, was carried out remotely (a call) around the third week after antivenom administration and not in a face-to-face clinical evaluation. This late monitoring strategy may have compromised our ability to identify this complication, which has a broad spectrum of clinical manifestations.

\section{Limitations}

This study has some limitations. Although it was carried out in a healthcare unit specialized in the treatment of snake envenoming, prospectively, for a period of one year and with the support of a dedicated health team acting under clinical protocols, the sample gathered here is still too small to allow comparisons between antivenoms produced by the four manufacturers in Brazil. In view of the intrinsic variability involved in snake envenoming, phase IV studies, such as this one, are the most viable alternative for assessing the safety and effectiveness of antivenoms and are strongly recommended by the $\mathrm{WHO}^{14,38}$. Thus, despite the limitations, we believe that we have produced a reliable report of the frequency and seriousness of adverse events related to Crotalic and Bothropic antisera currently in use in Brazil.

\section{CONCLUSION}

In general, our results suggest that although frequent, infusion reactions related to antivenom sera are, in most cases, of mild to moderate intensity, with characteristics compatible with type I hypersensitivity reactions. The rate of serious infusion reactions was $9 \%$, affecting respiratory and haemodynamic stability, but this rate was completely reversed with specific treatment. Only one patient developed symptoms compatible with serum sickness. The occurrence of life-threatening respiratory manifestations warns of the 
need to equip the healthcare units responsible for antivenom serum administration with the minimum necessary infrastructure and periodic training of health professionals. In addition, the disease requires a decentralized health system organization able to provide quick access to the population most affected by the problem: those living in rural areas, far from urban centres. Further multicentre studies gathering larger samples are needed to answer unresolved questions, such as the existence of a difference in the safety profile between antivenoms for the different snake species, as well as to identify possible individual markers related to the occurrence of acute and late adverse events related to the antivenom sera. From a global perspective, an integrated multifocal approach targeting complex problems and involving many participants is necessary ${ }^{39,40}$. Among the requirements are the strengthening of the technological capacity of the laboratories around the world to produce high-quality sera, the development of antivenom distribution programs tailored to the real needs and epidemiological situations of rural areas and permanent training programs for health staff in remote areas.

\section{ACKNOWLEDGMENTS}

To the patients and professionals of the Toxicology Service of Hospital Joao XXIII who collaborated with this study. GC is currently receiving a grant from $\mathrm{CNPq}, \mathrm{N}^{\circ}$ 301384/2019.

\section{AUTHORS' CONTRIBUTIONS}

Conception: DCSN, GC and RMMS; study design: DCSN, GC, RMMS and AAF; data collection: DCSN and IPC; analysis and interpretation of the data: DCSN and GC; drafting of the paper: DCSN and GC; revising the paper critically for intellectual contents and final approval of the version to be published: DCSN, IPC, RMMS, AAF and GC.

\section{CONFLICT OF INTERESTS}

No potential conflict of interests was reported by the authors.

\section{REFERENCES}

1. Gutiérrez JM, Calvete JJ, Habib AG, Harrison RA, Williams DJ, Warrell DA. Snakebite envenoming. Nat Rev Dis Primers. 2017;3:17063.

2. World Health Organization. Snakebite envenoming. [cited 2021 Jul 29]. Available from: https://www.who.int/en/news-room/ fact-sheets/detail/snakebite-envenoming
3. Longbottom J, Shearer FM, Devine M, Alcoba G, Chappuis F, Weiss DJ, et al. Vulnerability to snakebite envenoming: a global mapping of hotspots. Lancet. 2018;392:673-84.

4. World Health Organization. Snakebite envenoming: a strategy for prevention and control, Geneva: WHO; 2019. [cited 2021 Jul 29]. Available from: https://apps.who.int/iris/bitstream/ha ndle/10665/324838/9789241515641-eng.pdf?ua=1

5. Brasil. Ministério da Saúde. Doenças e agravos de notificação - 2007 em diante (SINAN): acidentes por animais peçonhentos. [cited $2021 \mathrm{Jul} 29$ ]. Available from: http://www2.datasus.gov.br/DATASUS/index. php?area $=0203 \& i d=29878153 \& \mathrm{VObj}=$ http: $/ /$ tabnet.datasus. gov.br/cgi/deftohtm.exe?sinannet/cnv/animais

6. Chippaux JP. Incidence and mortality due to snakebite in the Americas. PLoS Negl Trop Dis. 2017;11:e0005662.

7. Harrison RA, Hargreaves A, Wagstaff SC, Faragher B, Lallo DG. Snake envenoming: a disease of poverty. PLoS Negl Trop Dis. 2009;3:e569.

8. Chippaux JP, Goyffon M. Venoms, antivenoms and immunotherapy. Toxicon. 1998;36:823-46.

9. Theakston RD, Warrel DA, Griffiths E. Report of a WHO workshop on the standardization and control of antivenoms. Toxicon. 2003;41:541-57.

10. Williams DJ, Faiz MA, Abela-Ridder B, Ainsworth S, Bulfone TC, Nickerson AD, et al. Strategy for a globally coordinated response to a priority neglected tropical disease: snakebite envenoming. PLoS Negl Trop Dis. 2019;13:e0007059.

11. Fan HW, Marcopito LF, Cardoso JL, França FO, Malaque CM, Ferrari RA, et al. Sequential randomised and double-blind trial of promethazine prophylaxis against early anaphylactic reactions to antivenom for bothrops snake bites. BMJ. 1999;318:1451-2.

12. Mendonça-da-Silva I, Tavares AM, Sachett J, Sardinha JF, Zaparolli L, Santos MF, et al. Safety and efficacy of a freezedried trivalent antivenom for snakebites in the Brazilian Amazon: an open randomized controlled phase IIb clinical trial. PLoS Negl Trop Dis. 2017;11:e006068.

13. Bush SP, Ruha AM, Seifert SA, Morgan DL, Lewis BJ, Arnold $\mathrm{TC}$, et al. Comparison of $\mathrm{F}\left(\mathrm{ab}^{\prime}\right) 2$ versus $\mathrm{Fab}$ antivenom for pit viper envenomation: a prospective, blinded, multicenter, randomized clinical trial. Clin Toxicol (Phila). 2015;53:37-45.

14. Williams DJ, Habib AG, Warrell DA. Clinical studies of the effectiveness and safety of antivenoms. Toxicon. 2018;150:1-10.

15. Léon G, Herrera M, Segura A, Villalta M, Vargas M, Gutiérrez JM. Pathogenic mechanisms underlying adverse reactions induced by intravenous administration of snake antivenoms. Toxicon. 2013;76:63-76.

16. Fan HW. Soroterapia. In: Cardoso JL, França FO, Wen FH, Málaque CM, Haddad Jr V, editores. Animais peçonhentos do Brasil: biologia, clínica e terapêutica dos acidentes. $2^{\mathrm{a}}$ ed. São Paulo: Sarvier; 2009. p.432-45. 
17. von Elm E, Altman DG, Egger M, Pocock SJ, Gøtzsche PC, Vandenbroucke JP. The Strengthening the Reporting of Observational Studies in Epidemiology (STROBE) statement: guidelines for reporting observational studies. Ann Intern Med. 2007;147:573-7.

18. Brasil. Ministério da Saúde. Fundação Nacional de Saúde. Manual de diagnóstico e tratamento de acidentes por animais peçonhentos. $2^{\mathrm{a}}$ ed. rev. Brasília: FUNASA; 2001. [cited 2020 Mar 20]. Available from: https://www.icict.fiocruz.br/ sites/www.icict.fiocruz.br/files/Manual-de-Diagnostico-eTratamento-de-Acidentes-por-Animais-Pe--onhentos.pdf

19. United States of America. National Cancer Institute. Cancer Therapy Evaluation Program. Common Terminology Criteria for Adverse Events (CTCAE). [cited 2021 Jul 29]. Available from: https://ctep.cancer.gov/protocoldevelopment/electronic_ applications/ctc.htm

20. Brasil. Ministério da Saúde. Agência Nacional de Vigilância Sanitária. Resolução da Diretoria Colegiada - RDC n 09, de 20 de fevereiro de 2015. Dispõe sobre o regulamento para a realização de ensaios clínicos com medicamentos no Brasil. Diário Oficial da União, Brasília, 3 mar. 2015. [cited 2021 Jul 29]. Available from: http://antigo.anvisa.gov.br/ documents/10181/3503972/RDC_09_2015_COMP.pdf

21. World Health Organization. Uppsala Monitoring Centre. The use of the WHO-UMC system for standardised case causality assessment. [cited $2021 \mathrm{Jul}$ 29]. Available from: https://www. who-umc.org/media/164200/who-umc-causality-assessment_ new-logo.pdf

22. Ralph R, Sharma SK, Faiz MA, Ribeiro I, Rijal S, Chappuis F, et al. The timing is right to end snakebite deaths in South Asia. BMJ. 2019;364:k5317.

23. Silva HA, Ryan NM, Silva HJ. Adverse reactions to snake antivenom, and their prevention and treatment. Br J Clin Pharmacol. 2016;81:446-52.

24. Khobrani M, Huckleberry Y, Boesen KJ, Aljabri A, Alharthi $\mathrm{M}$, Patanwala $\mathrm{AE}$, et al. Incidence of allergic reactions to Crotalidae polyvalent immune Fab. Clin Toxicol (Phila). 2019;57:164-7.

25. Andrade Filho A, Campolina D, Dias MB. Ofidismo. In: Andrade Filho A, Campolina D, Dias MB, editores. Toxicologia na prática clínica. $2^{\text {a }}$ ed. Belo Horizonte: Folium; 2013. p.491510.

26. Pugh RN, Theakston RD. Antivenom reactions and complement depletion in snake bite. Ann Trop Med Parasitol. 1987;81:73-5.

27. Isbister GK, Shahmy S, Mohamed F, Abeysinghe C, Karunathilake $\mathrm{H}$, Ariaratnam A. A randomised controlled trial of two infusion rates to decrease reactions to antivenom. PLoS One. 2012;7:e38739.

28. Amin Mr, Mamun SM, Rashid R, Rahman M, Ghose A, Sharmin $\mathrm{S}$, et al. Anti-snake venom: use and adverse reaction in a snake bite study clinic in Bangladesh. J Venom Anim Toxins Incl Trop Dis. 2008;14:660-72.

29. Schaeffer TH, Khatri V, Reifler LM, Lavonas EJ. Incidence of immediate hypersensitivity reaction and serum sickness following administration of Crotalidae polyvalent immune Fab antivenom: a meta-analysis. Acad Emerg Med. 2012;19:121-31.

30. Caiaffa WT, Vlahov D, Antunes CM, Oliveira HR, Diniz CR. Snakebite and antivenom complications in Belo Horizonte, Brazil. Trans R Soc Trop Med Hyg. 1994;88:81-5.

31. Amaral CF, Campolina D, Dias MB, Bueno CM, Olortequi CC, Penaforte CL, et al. Time factor in the detection of circulating whole venom and crotoxinand efficacy of antivenom therapy in patients envenomed by Crotalus durissus. Toxicon. 1997;35:699-704.

32. Cardoso JL, Fan HW, França FO, Jorge MT, Leite RP, Nishioka $\mathrm{SA}$, et al. Randomized comparative trial of three antivenoms in the treatment of envenoming by lance-headed vipers (Bothrops jararaca) in Sao Paulo, Brazil. Q J Med. 1993;86:315-25.

33. Borges CC, Sadahiro M, Santos MC. Aspectos epidemiológicos e clínicos dos acidentes ofídicos ocorridos nos municípios do Estado do Amazonas. Rev Soc Bras Med Trop. 1999;32:637-46.

34. Smalligan R, Cole J, Brito N, Laing GD, Mertz BL, Manock S, et al. Crotaline snake bite in the Ecuadorian Amazon: randomised double blind comparative trial of three South American polyspecific antivenoms. BMJ. 2004;329:1129.

35. Alirol E, Sharma SK, Bawaskar HS, Kuch U, Chappuis F. Snake bite in South Asia: a review. PLoS Negl Trop Dis. 2010;4:e603.

36. Mong R, Ng VC, Tse ML. Safety profile of snake antivenom (use) in Hong Kong: a review of 191 cases from 2008 to 2015. Clin Toxicol (Phila). 2017;55:1066-71

37. LoVecchio F, Klemens J, Roundy EB, Klemens A. Serum sickness following administration of Antivenin (Crotalidae) Polyvalent in 181 cases of presumed rattlesnake envenomation. Wilderness Environ Med. 2003;14:220-1.

38. World Health Organization. Guidelines for the production, control and regulation of snake antivenom immunoglobulins: replacement of Annex 2 of WHO Technical Report Series, $\mathrm{N}^{\circ}$ 964. [cited 2021 Jul 29]. Available from: https://www.who. int/bloodproducts/AntivenomGLrevWHO_TRS_1004_web_ Annex_5.pdf

39. Fan HW, Vigilato MA, Pompei JC, Gutiérrez JM. Situación de los laboratorios públicos productores de antivenenos en América Latina. Rev Panam Salud Publica. 2019;43:e92.

40. Gutiérrez JM, Williams D, Fan HW, Warrell DA. Snakebite envenoming from a global perspective: towards an integrated approach. Toxicon. 2010;56:1223-35.

Supplementary Material available from: https://doi.org/10.48331/scielodata.LLDEYG 